\title{
Clinical and radiological evaluation of cervical disc arthroplasty with 5-year follow-up: a prospective study of 384 patients
}

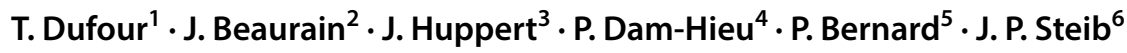

Received: 25 October 2018 / Revised: 5 April 2019 / Accepted: 12 June 2019 / Published online: 30 July 2019

(c) The Author(s) 2019

\begin{abstract}
Background Cervical total disc replacement was developed to avoid known complications of cervical fusion. The purpose of this paper was to provide 5-year follow-up results of an ongoing prospective study after implantation of cervical disc prosthesis.

Methods Three hundred and eighty-four patients were treated using Mobi-C cervical disc (Zimmer Biomet, Troyes, France) and included in a prospective multicentre study. Routine clinical and radiological examinations were reported preoperatively and postoperatively with up to 5-year follow-up. Complications and revision surgeries were also explored.

Results Results at 5 years showed significant improvement in all clinical outcomes (NDI, VAS for arm and neck pain, SF-36 PCS and MCS). Motion at index level increased significantly from $6.0^{\circ}$ preoperatively to $8.0^{\circ}$, and $72.1 \%$ of the implanted segments were still mobile (referring to threshold of ROM $>3^{\circ}$ ). Proximal and distal adjacent discs showed no significant change in average motion 5 years after surgery compared to baseline. Ossification resulting in complete fusion was observed in $16.4 \%$ of the implanted segments. Distal and proximal adjacent disc degeneration occurred in $42.2 \%$ and $39.1 \%$ of patients, respectively. Complications rate was $8.9 \%$, and $1.5 \%$ of the patients had reoperation at the index level. Surgery rate of adjacent discs was $2.9 \%$. An increased percentage of working patients and a decrease in medication consumption were observed. At 5 years, $93.3 \%$ patients were satisfied regarding the overall outcome.

Conclusions In this study, favourable 5-year follow-up clinical and radiological outcomes were observed with a low rate of adjacent level surgery.
\end{abstract}

\section{Graphic abstract}

These slides can be retrieved under Electronic Supplementary Material.
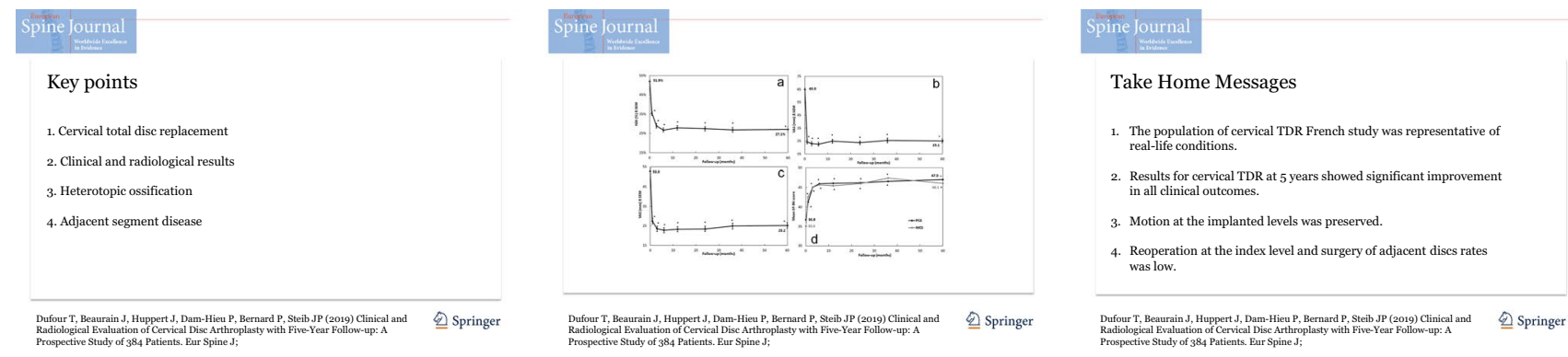

Keywords Cervical total disc replacement $\cdot$ Mobi-C $\cdot$ Clinical results $\cdot$ Radiological results $\cdot$ Heterotopic ossification · Adjacent segment disease

Electronic supplementary material The online version of this article (https://doi.org/10.1007/s00586-019-06069-z) contains supplementary material, which is available to authorized users.

Extended author information available on the last page of the article 


\section{Introduction}

After failure of conservative treatment in patients with cervical degenerative disc disease, anterior cervical discectomy and fusion (ACDF) was the traditional standard surgical procedure [1-3]. Although ACDF typically relieves pain significantly, pseudarthrosis occurs in some patients, and the elimination of motion at the index level in the others may result in adjacent level degeneration [4-6].

Cervical total disc replacement (CTDR) was developed as an alternative treatment, in order to avoid drawbacks of ACDF by replacing the degenerative discs and preserving physiological cervical function [7-9]. A large number of arthroplasty devices have been developed [7, 10]. Previous published studies have established that CTDR provides pain relief and functional improvements similar or superior to those of ACDF with lower rates of adjacent segment degeneration [11-13].

The present study aimed to investigate the efficacy and safety of a cervical disc prosthesis (Mobi-C, Zimmer Biomet, Troyes, France) with 5-year follow-up (FU). The 2-year intermediate results already published $[14,15]$ demonstrated encouraging clinical and radiological performance and preservation of the status of the adjacent levels.

\section{Materials and methods}

\section{Study design}

Between November 2004 and August 2009, 384 patients had surgery with the Mobi-C cervical disc prosthesis (Fig. 1) in this observational, prospective and multicentre study involving eight centres in France. The study will be pursued until 10 years of $\mathrm{FU}$ is attained.

The indication was degenerative cervical discopathy at one or more levels of the cervical spine leading to chronic and disabling radiculopathy, spondylotic and discogenic myelopathy, or both, resistant to well-conducted medical treatment. Diagnosis was confirmed by imaging (CT, MRI and X-rays).

Exclusion criteria were osteoporosis, non-adherence to the protocol, metabolic bone disease, congenital or posttraumatic deformity, infection, neoplasia, instability of the interbody space or cervical canal stenosis $(<12 \mathrm{~mm})$. Previous cervical spine surgery (including surgery at the index level), work-related injury and learning curve cases were not exclusion criteria.

\section{Outcomes}

Each patient was followed up prospectively with preoperative and regular post-operative evaluations for 5 years ( 1 ; $3 ; 6 ; 12 ; 24 ; 36$; and 60 months). Clinical outcomes were determined by a self-assessment questionnaire that included the Neck Disability Index (NDI, 0-100\%), visual analogue scale (VAS, 0-100 mm) arm and neck pain scores and Medical Outcomes Survey Short Form-36 (SF-36) summarized by the physical (PCS) and mental (MCS) component scores. Standardized questions relating to patient satisfaction, medication consumption and employment status were likewise completed at each FU stage of the investigation. Study did not plan medication guideline for pain neither in $\mathrm{HO}$ prevention. Adverse events were monitored and
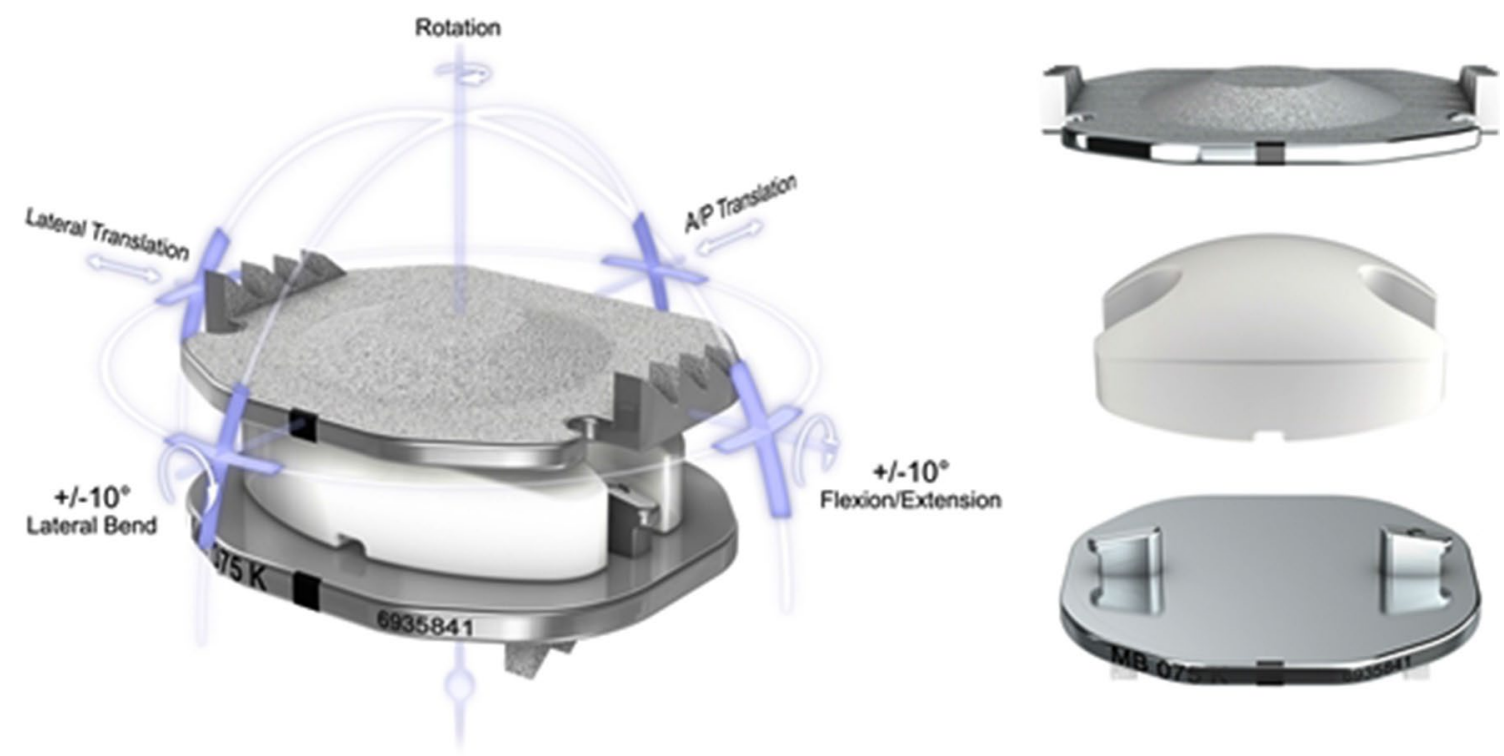

Fig. 1 Mobi-C® cervical disc, level of mobility and components including proximal and distal endplate and central polyethylene core 
recorded. Additional surgeries at index or adjacent levels were reported. Dynamic radiographs were obtained at each visit to assess the range of motion (ROM) at index and adjacent levels with the SpineView software (Surgiview, France). The extent of heterotopic ossifications (HO) was graded according to Mehren-McAfee classification [16, 17] by a senior spine surgeon who was blinded to the clinical status. Adjacent segment degeneration was scored, by two investigators, according to Kellgren-Lawrence grading system (grades 0-4) [18] using the figures and legends of the atlas of standard radiographs, in which grade 0 or 1 denotes no or minimal anterior osteophytosis, grade 2 denotes definite anterior osteophytosis with possible narrowing of disc space and some sclerosis of vertebral plates, and grades 3 and 4 indicate moderate narrowing of disc space with definite sclerosis of vertebral plates and osteophytosis or severe narrowing of disc space with sclerosis of vertebral plates and multiple large osteophytes [19].

\section{Statistical analysis}

All available data were taken into account. The paired t test was used for comparisons between preoperative and postoperative continuous data. The McNemar's test was used for comparison of categorical data. The significance level was $p<0.05$. Statistical analyses were conducted using the statistical program R (version 3.3.2; https://www.R-project.org).

\section{Results}

Three hundred and eighty-four patients received 535 prostheses and agreed to enroll in the FU phase. Demographic information, preoperative status and surgical data are reported in Table 1. Overall, 85.6\% (328/383) of the patients had no previous cervical surgery, and $12.0 \%$ (46/383) had a previous fusion at index and/or adjacent and/or distant levels. Taking into account premature withdrawals from the study, at 5 years, the expected number of patients was 371, and FU rate was 80.6\% (299/371). Figure 2 illustrates dynamic 5-year post-operative $\mathrm{X}$-rays (flexion/extension) for one- and two-level procedures.

Statistically significant improvements in all clinical outcomes were noted at all FU examinations (Fig. 3). Disability assessed by NDI and VAS for arm and neck pain decreased significantly from baseline to each FU. The mean NDI improvement at 5-year FU was $24.2 \%$ (95\% CI $21.8 \%$ to $26.5 \%, p<0.001)$, VAS arm pain improved $38.7 \mathrm{~mm}$ (95\% CI $34.6-42.8 \mathrm{~mm}, p<0.001)$, and VAS neck pain improved $26.6 \mathrm{~mm}$ (95\% CI $23.0-30.2 \mathrm{~mm}$, $\mathrm{p}<0.001)$. SF-36 score from baseline to 5 years improved with increases of 9.7 (95\% CI 8.4-11.0, $p<0.001)$ and
Table 1 Demographic information, preoperative status and surgical data

\begin{tabular}{llll}
\hline & Mean \pm SD or $n$ or $\%$ & Range & $n$ \\
\hline Age (years) & $44.8 \pm 8.1$ & $23-73$ & 384 \\
Gender & 169 males & 384 \\
& 215 females & & \\
Duration of symptoms & <1 year: 52.4\% & 368 \\
& 1-4 years: 29.1\% & \\
& $>4$ years: $18.5 \%$ & & \\
Number of operated level & 1 level: $66.9 \%$ & 384 \\
& 2 levels: $28.1 \%$ & & \\
& 3 levels: $3.6 \%$ & & \\
& 4 levels: $1.3 \%$ & & \\
& C3-C4: $2.4 \%$ & & \\
Operated level & C4-C5: $12.2 \%$ & & \\
& C5-C6: $43.7 \%$ & & \\
& C6-C7: $40.8 \%$ & & 372 \\
\hline
\end{tabular}

10.9 (95\% CI 9.1-12.6, $p<0.001)$ for PCS and MCS, respectively.

Mean preoperative and post-operative ROM are presented in Fig. 4. At 5-year FU, motion at the index levels was significantly increased (mean $\mathrm{ROM}=8.0^{\circ}$ vs. $6.0^{\circ}$ preoperatively) and $72.1 \%$ of the implanted segments were still mobile, with mobility defined as flexion-extension ROM $>3^{\circ}$. Adjacent discs showed no significant change in ROM compared to baseline and the large majority exhibited only mild or no degeneration. The incidence of adjacent segment degeneration is presented in Table 2. Overall, 39.1\% (91/233) and $42.2 \%(54 / 128)$ of proximal and distal adjacent discs, respectively, showed some increase in degeneration 5 years after surgery. Grade $4 \mathrm{HO}$ occurred in $16.4 \%$ (48/406) of the implanted segments at 5 years, grade $3 \mathrm{HO}$ in 6.8\% (20/406), grade 2 in 39.4\% (115/406), grade 1 in 14.4\% (42/406) and grade 0 in $22.9 \%$ (67/406).

Amongst all the 384 patients enrolled, 34 patients (8.9\%) experienced 41 adverse events (device/surgery-related, with/ without reoperation) during their FU. There was no expulsion of the device, no device failure and no vertebral body fracture. Reoperation for device removal or repositioning was performed in $1.5 \%$ of the patients (6/384). In addition, 11 patients $(2.9 \%)$ were surgically treated for adjacent disc disease (ADD): four were considered as development of a new symptomatic ADD, and the other seven had already an ADD considered as minor before the index surgery.

With regard to medication consumption, the rate of patients using analgesics decreased significantly from $83.2 \%$ (297/357) before surgery to $28.6 \%(76 / 266)$ at 5 years. Professional status was significantly upgraded at 5 years with 
Fig. 2 Dynamic radiographs 5 years after implantation for one- and two-level CTDRs
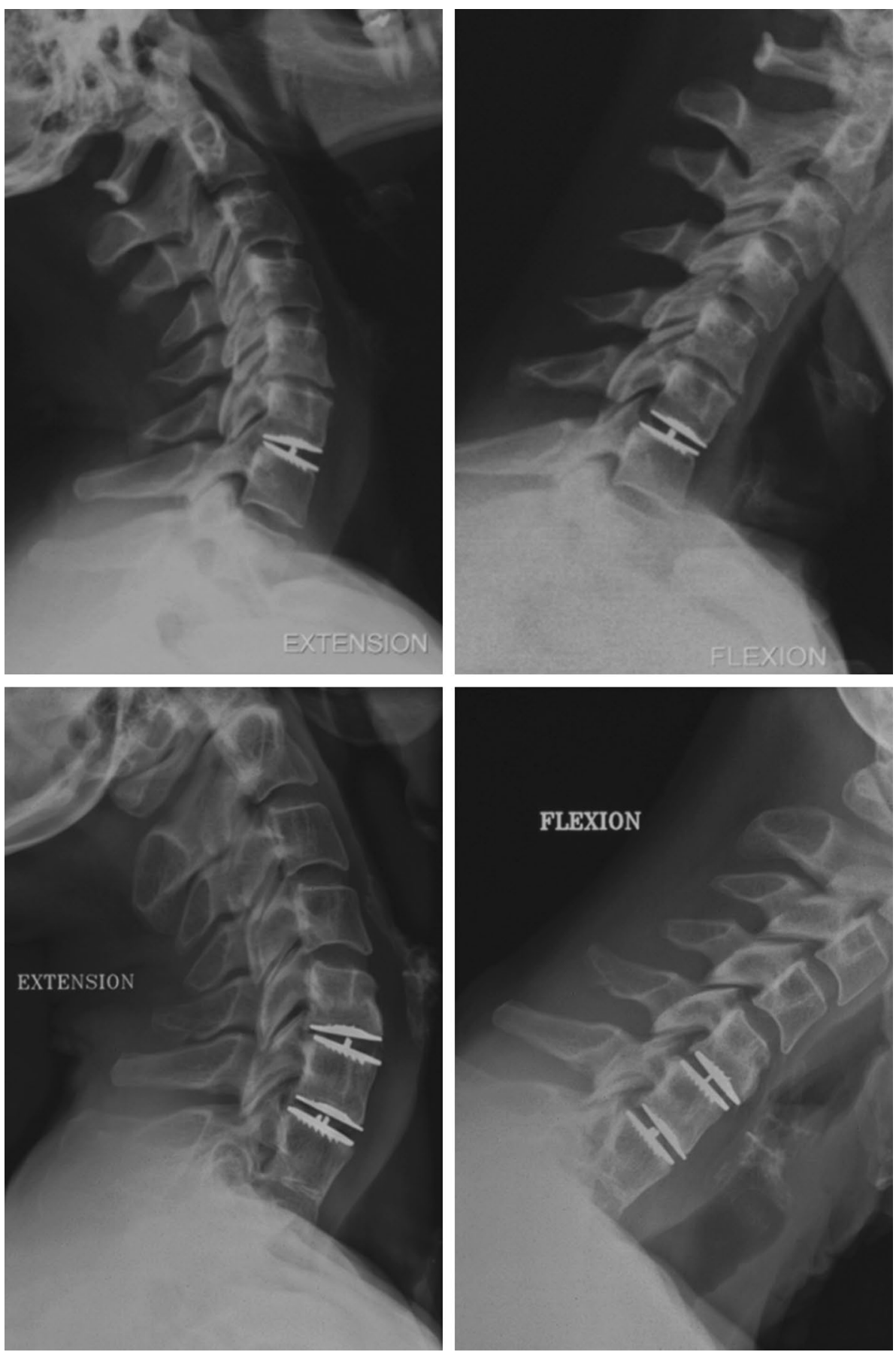

FLEXION

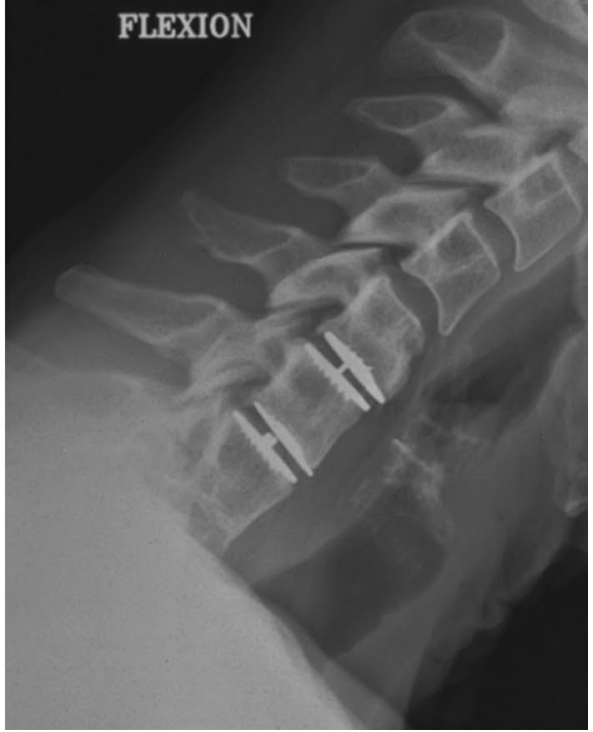

an increase in working patients, from $35.6 \%$ (136/382) preoperatively to $59.3 \%(166 / 280)$, and a decrease in patients on sick leave from $51.8 \%$ (198/382) preoperatively to $5.7 \%$ (16/280). At 5 years, patient satisfaction regarding cervical and arm pain was $80.4 \%(225 / 280)$ and $75.5 \%$ (210/278), respectively, and $93.3 \%$ (263/282) answered yes to the question "Would you undergo the procedure again?".

\section{Discussion}

The present study was designed to assess both clinical and radiological outcomes of a cervical disc prosthesis. The results of this investigation demonstrated that clinical outcomes have improved at all time points after surgery until final FU, with statistical significance, compared to baseline. Preservation of mobility at index level and a low operation rate for adjacent disc disease were also observed. 

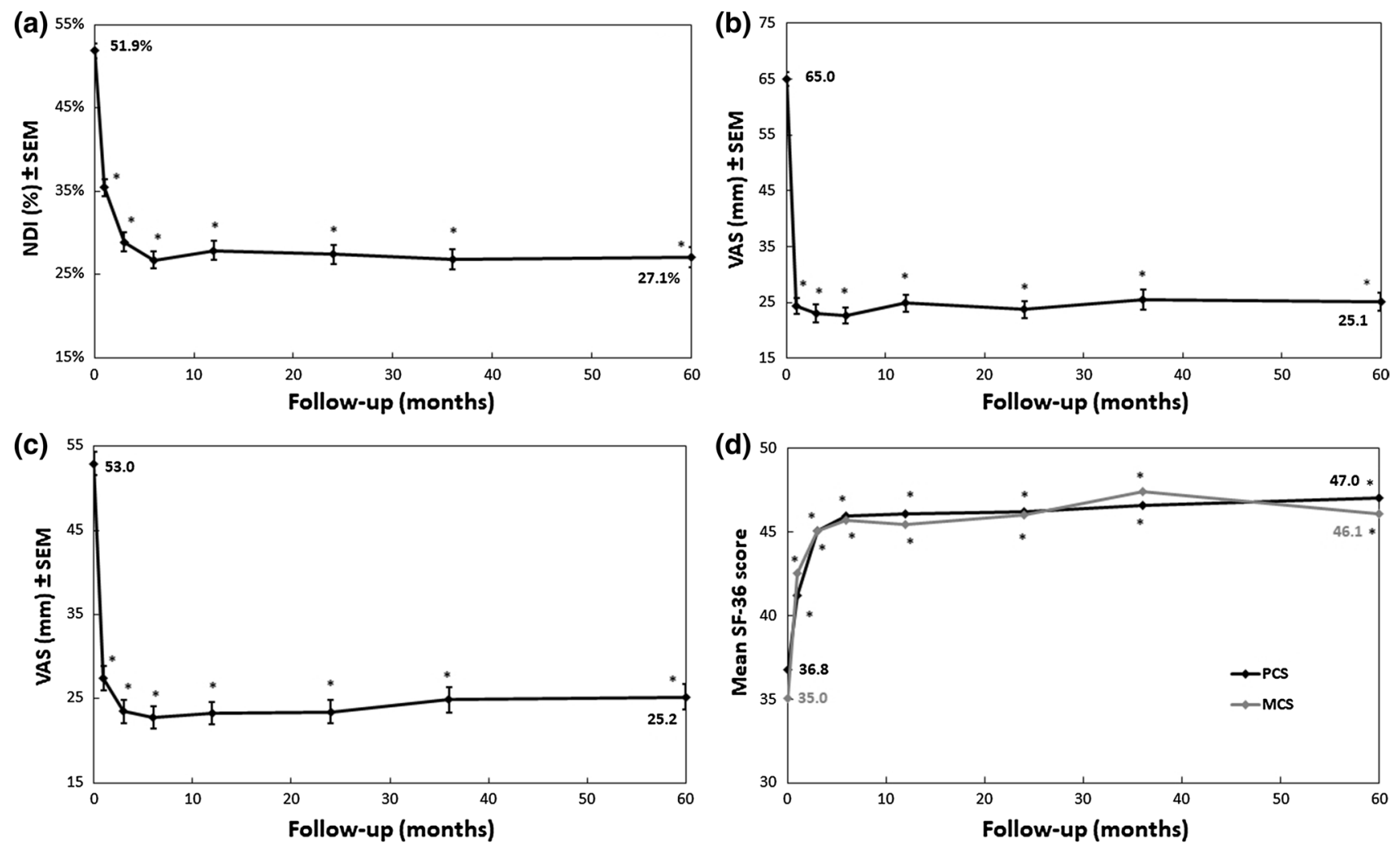

Fig. 3 Clinical outcomes over follow-up. Results are expressed as mean \pm SEM. ${ }^{*} p \leq 0.05$ compared to preoperative baseline: a Neck Disability Index (NDI, 0-100\%). b Visual analogue scale (VAS,

0-100 mm) for arm pain. c Visual analogue scale (VAS, 0-100 mm) for neck pain. d SF-36 PCS and MCS
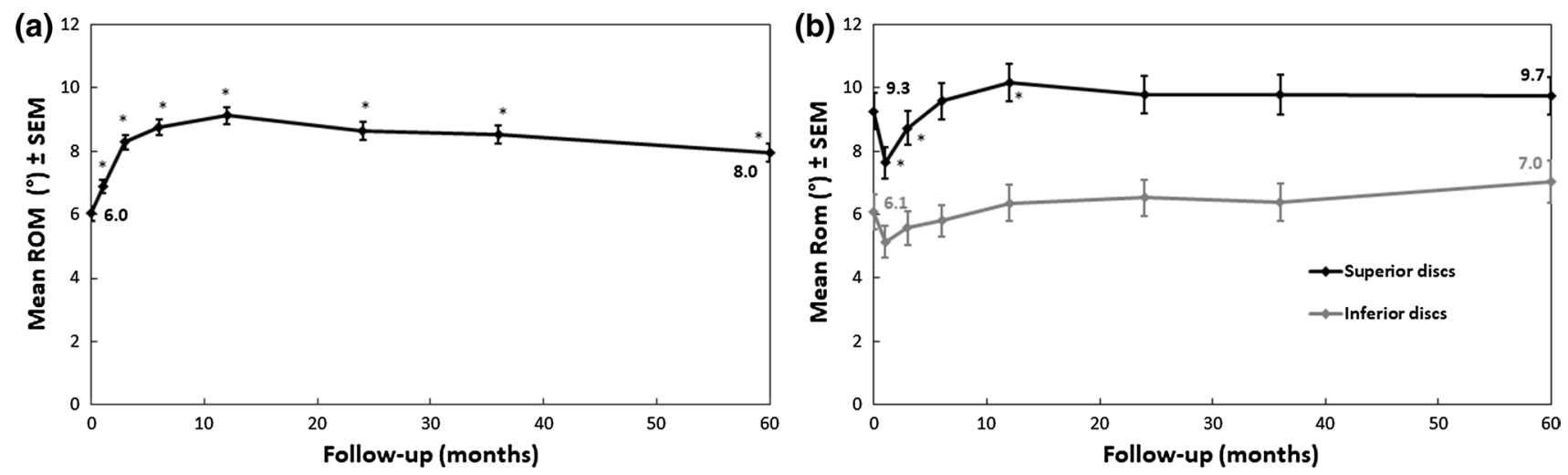

Fig. 4 Radiological outcomes over follow-up. Results are expressed as mean \pm SEM. $* p \leq 0.05$ compared to preoperative baseline: a ROM at the index level. b ROM at adjacent levels

Several studies have been conducted to investigate the effectiveness of CTDR as a viable alternative to ACDF [20-28]. The major advantage of CTDR, aside from pain relief, has been preservation of mobility at index levels and a subsequent low incidence of ADD, a high rate of which after ACDF has long been criticized [29, 30].

With regard to relief of symptoms, the present results at 5-year FU demonstrated statistically significant improvement for NDI, VAS for arm and neck pain and SF-36 results for both PCS and MCS. Similar observations have been reported in a number of studies evaluating the clinical efficacy of CTDR using various prostheses $[4,14,20-23,25,27,28$, $31]$. These findings were clearly supported by meta-analysis studies $[12,13]$.

In response to motion preservation, radiological results showed significant improvement at 5 years with a mean 
Table 2 Incidence of adjacent levels degeneration according to Kellgren-Lawrence classification preoperatively and at 5-year (M60) FU

\begin{tabular}{llllll}
\hline Grade & \multicolumn{2}{l}{ Proximal adjacent discs } & & \multicolumn{2}{l}{ Distal adjacent discs } \\
\cline { 2 - 3 } \cline { 5 - 6 } \cline { 5 - 6 } & $\begin{array}{l}\text { Preop } \\
(n=296)(\%)\end{array}$ & $\begin{array}{l}\text { M60 } \\
(n=263)(\%)\end{array}$ & & $\begin{array}{l}\text { Preop } \\
(n=201)(\%)\end{array}$ & $\begin{array}{l}\text { M60 } \\
(n=171) \\
(\%)\end{array}$ \\
\hline Grade 0 & 55.4 & 35.0 & 73.1 & 50.9 \\
Grade 1 & 28.7 & 42.2 & & 14.4 & 28.7 \\
Grade 2 & 10.5 & 14.8 & & 8.0 & 13.5 \\
Grade 3 & 4.4 & 6.5 & 3.5 & 6.4 \\
Grade 4 & 1.0 & 1.5 & 1.0 & 0.6 \\
\hline
\end{tabular}

ROM of $8^{\circ}$ and $72.1 \%$ of implanted prostheses maintaining mobility above a threshold of $3^{\circ}$. In two prospective, randomized, controlled trials comparing the same device with ACDF, similar mean ROM was reported at 5 years FU $\left(10.2^{\circ}\right.$ and $\left.9.3^{\circ}\right)[22,26,31]$. Likewise, this mean ROM was also in accordance with other mid- and long-term studies involving other devices which ranged from $6^{\circ}$ to $13^{\circ}[3,12,13,32]$. A threshold of $2^{\circ}$ has commonly been used to decide on the mobility of prostheses, possibly explaining why higher rates of mobility have been reported [21].

Occurrence of HO remains a potential drawback of CTDR [17, 33]. In this investigation, the characterization of the different grades showed that $\mathrm{HO}$ led to complete fusion (grade 4) in $16.4 \%$ of the implanted segments at 5 years. In a meta-analysis of 38 studies, Kong et al. (2017) found that overall prevalence of severe $\mathrm{HO}$ (grade $4 \mathrm{HO}$ ) was $17.0 \%$ (95\% CI 12.8-22.2\%), and in particular, for studies with 2- to 5-year FU was $22.2 \%$ (95\% CI 15.5-30.7\%) [34]. In a prospective, non-randomized study with long-term FU, grade $4 \mathrm{HO}$ was observed in $16.1 \%$ of cases at 5 years and in $26 \%$ at 10 years [24]. However, there was lower incidence observed at 5-year FU in an investigational device exemption (IDE) study of the present prosthesis, with $\mathrm{HO}$ reported in $8.5 \%$ of 1 -level patients and $9.7 \%$ of two-level patients [22, 26]. This difference may be due to stricter selection criteria in the IDE study.

Both orthopaedic and neurosurgeons were involved in the study. When the study operations were performed, the orthopaedic surgeons of the group were not yet using surgical microscopes. At present, the use of a microscope is recommended, because it improves the efficacy of posterior longitudinal ligament (PLL) release and osteophyte resection. Improved osteophyte resection might decrease the rate of grade $4 \mathrm{HO}$ after CTDR. Distraction might also reduce the incidence of this complication. In ACDF, distraction is beneficial, because it enlarges the foramens and reduces PLL buckling. Over distraction, however, is not recommended for CTDR, because it would lead to stretching of cervical facet joint capsules, a source of neck pain. Finally, large endplates that can be used today, were not available when the present study began. It has been found that proper endplate sizing may be an important factor for mitigating HO [35]. Larger plates in the front might have hindered fusion (grade $4 \mathrm{HO}$ ) in some cases by mechanically blocking some of the peripheral bone growth. In any event, grade $4 \mathrm{HO}$ after CTDR is probably no more frequent than pseudarthrosis following ACDF [36], and contrary to pseudarthrosis, clinical outcomes did not deteriorate in patients with grade $4 \mathrm{HO}$. Outcomes of CTDR patients with grade $4 \mathrm{HO}$ are similar to those of successfully fused ACDF patients.

Motion at adjacent levels showed a slight increase without statistical significance. There was evidence that fusion increased mobility at adjacent levels, with greater effect on proximal levels [29]. In addition, it is open to debate as to whether incidence of adjacent segment degeneration is related to natural degeneration or biomechanical stress as results of adjacent fusion [5, 6, 30]. While Hilibrand et al. reported an annual incidence rate of adjacent segment degeneration of $2.9 \%$ after fusion [37], Xia et al. noted $32.8 \%$ (95\% CI 17.8-47.9\%) occurrence of adjacent segment degeneration after cervical spine surgery [38]. The present study showed some further degeneration in $39.1 \%$ at the proximal adjacent level and in $42.2 \%$ at the distal adjacent level; similar results were observed in the IDE studies $[22,26]$. One of the more significant findings to emerge from the present study is the low rate of ADD surgery, performed in only $2.9 \%$ of patients at 5 years. This tend to support the protection of adjacent discs from ADD [39, 40]. In the literature, this rate is impacted by the design of the device itself [41] and rate ranged from $4 \%$ to as high as $16 \%$ after CTDR [21, 38].

There was a low adverse events rate reported in present study during 5 years of FU, with, in addition a low rate of reoperation at the index level. Dejaegher et al. reported in a 10-year follow-up after implantation of another cervical disc prosthesis 186 adverse events recorded for 73 patients, out of 89 included in the study, and $2 \%$ rate of reoperation at the index level. It has become common with recent publications to report that CTDRs have significantly lower rates of adverse events and reoperations than $\operatorname{ACDF}[3,11,13,32]$.

It should also be noted that medication consumption declined significantly and significant resumption of work was observed at 5-year FU. Despite the fact that cost-effectiveness data are country dependent, cost-effectiveness analyses regarding CTDR and ACDF for the treatment of one- or twolevel cervical degenerative disc disease have concluded that both CTDR and ACDF are cost-effective procedures, but that CTDR remained more cost-effective than ACDF [42-44]. Similarly, the present patients have maintained a high level of satisfaction 5 years after surgery.

One limitation of the present study is a potential selection bias arising from the fact that the study was not randomized. 
The lack of a control group partially limits the impact of the results. In particular, data on radiographic adjacent segment degeneration are less meaningful without a comparative control group. One limitation of this article is the absence of detail in the population profile stratification (age, multilevel, length of symptoms and comorbidities) that could impact results and bias the comparison with ACDF in the literature. Nonetheless, the present report provides real-world intermediate-term evidence that will hopefully help readers better evaluate how CTDR might contribute to their everyday clinical practice. Furthermore, in the present study, work-related injury cases and patients with previous arthrodesis of the cervical spine were not excluded.

In a meta-analysis comparing non-randomized observational studies with randomized controlled trials in cervical disc arthroplasty, Jee et al. concluded that prospective observational studies can achieve relevant outcomes and conclusions [45]. To go further, Grob et al. suggest not to discredit observational studies as a relevant source of evidence in spine surgery [46]. The present report describes the results of a large, multicentre uncontrolled observational study on cervical disc arthroplasty. Specifically, we have detailed the 5-year patient reported outcomes (NDI, VAS, SF-36 and patient satisfaction), radiographic ROM, adjacent segment degeneration, heterotopic ossification and reoperation rates.

\section{Conclusion}

After 5-year FU, results of CTDR in 384 patients demonstrated favourable clinical and radiological outcomes. All clinical outcomes were improved reflecting high patient satisfaction. Radiological evaluation shows that mean mobility of the index levels was maintained with no increase in the ROM at adjacent levels. Surgery for ADD was low compared to literature reports on ACDF and other CTDRs. Moreover, the low adverse events rate and low reoperation rate at the index levels tend to confirm the safety and efficacy of the present CTDR system.

Funding This work was supported by LDR Médical (now Zimmer Biomet). Each of the authors is an investigator in the Mobi-C prospective multicentre study.

\section{Compliance with ethical standards}

Conflict of interest Each of the authors is an investigator of the multicenter Mobi-C prospective study. Dufour, Beaurain, Huppert, Bernard and Steib are also co-designers of Mobi-C and have received royalties from Zimmer Biomet. Prof. Dam Hieu has no conflict of interest in relation to this study. We have disclosures with other medical companies unrelated to this study. Dr. Dufour is a consultant for the Zeiss microscope company. Pr Steib is a consultant for Clariance and Medtronic. Dr. Bernard is a consultant for OSD.
Open Access This article is distributed under the terms of the Creative Commons Attribution 4.0 International License (http://creativeco mmons.org/licenses/by/4.0/), which permits unrestricted use, distribution, and reproduction in any medium, provided you give appropriate credit to the original author(s) and the source, provide a link to the Creative Commons license, and indicate if changes were made.

\section{References}

1. Cloward RB (1958) The anterior approach for removal of ruptured cervical disks. J Neurosurg 15(6):602-617. https://doi. org/10.3171/jns.1958.15.6.0602

2. Smith GW, Robinson RA (1958) The treatment of certain cervical-spine disorders by anterior removal of the intervertebral disc and interbody fusion. J Bone Jt Surg Am 40 (3):607-624

3. Xie L, Liu M, Ding F, Li P, Ma D (2016) Cervical disc arthroplasty (CDA) versus anterior cervical discectomy and fusion (ACDF) in symptomatic cervical degenerative disc diseases (CDDDs): an updated meta-analysis of prospective randomized controlled trials (RCTs). SpringerPlus 5(1):1188. https://doi. org/10.1186/s40064-016-2851-8

4. Zigler JE, Delamarter R, Murrey D, Spivak J, Janssen M (2013) ProDisc-C and anterior cervical discectomy and fusion as surgical treatment for single-level cervical symptomatic degenerative disc disease: five-year results of a Food and Drug Administration study. Spine 38(3):203-209. https://doi.org/10.1097/ BRS.0b013e318278eb38

5. Matsumoto M, Okada E, Ichihara D, Watanabe K, Chiba K, Toyama Y, Fujiwara H, Momoshima S, Nishiwaki Y, Iwanami A, Ikegami T, Takahata T, Hashimoto T (2010) Anterior cervical decompression and fusion accelerates adjacent segment degeneration: comparison with asymptomatic volunteers in a ten-year magnetic resonance imaging follow-up study. Spine 35(1):36-43. https://doi.org/10.1097/BRS.0b013e3181b8a80d

6. Helgeson MD, Bevevino AJ, Hilibrand AS (2013) Update on the evidence for adjacent segment degeneration and disease. Spine J 13(3):342-351. https://doi.org/10.1016/j.spinee.2012.12.009

7. Murtagh R, Castellvi AE (2014) Motion preservation surgery in the spine. Neuroimaging Clin N Am 24(2):287-294. https:// doi.org/10.1016/j.nic.2014.01.008

8. Le H, Thongtrangan I, Kim DH (2004) Historical review of cervical arthroplasty. Neurosurg Focus 17(3):E1. https://doi. org/10.3171/foc.2004.17.3.1

9. Bono CM, Garfin SR (2004) History and evolution of disc replacement. Spine J 4(6 Suppl):145S-150S. https://doi. org/10.1016/j.spinee.2004.07.005

10. Turel MK, Kerolus MG, Adogwa O, Traynelis VC (2017) Cervical arthroplasty: what does the labeling say? Neurosurg Focus 42(2):E2. https://doi.org/10.3171/2016.11.FOCUS16414

11. Xu B, Ma JX, Tian JH, Ge L, Ma XL (2017) Indirect meta-analysis comparing clinical outcomes of total cervical disc replacements with fusions for cervical degenerative disc disease. Sci Rep 7(1):1740. https://doi.org/10.1038/s41598-017-01865-3

12. Gao F, Mao T, Sun W, Guo W, Wang Y, Li Z, Abhinav P (2015) An updated meta-analysis comparing artificial cervical disc arthroplasty (CDA) versus anterior cervical discectomy and fusion (ACDF) for the treatment of cervical degenerative disc disease (CDDD). Spine 40(23):1816-1823. https://doi. org/10.1097/BRS.0000000000001138

13. Hu Y, Lv G, Ren S, Johansen D (2016) Mid- to long-term outcomes of cervical disc arthroplasty versus anterior cervical discectomy and fusion for treatment of symptomatic cervical disc disease: a systematic review and meta-analysis of 
eight prospective randomized controlled trials. PLoS ONE 11(2):e0149312. https://doi.org/10.1371/journal.pone.0149312

14. Beaurain J, Bernard P, Dufour T, Fuentes JM, Hovorka I, Huppert J, Steib JP, Vital JM, Aubourg L, Vila T (2009) Intermediate clinical and radiological results of cervical TDR (Mobi-C) with up to 2 years of follow-up. Eur Spine J 18(6):841-850. https://doi.org/10.1007/s00586-009-1017-6

15. Huppert J, Beaurain J, Steib JP, Bernard P, Dufour T, Hovorka I, Stecken J, Dam-Hieu P, Fuentes JM, Vital JM, Vila T, Aubourg L (2011) Comparison between single- and multi-level patients: clinical and radiological outcomes 2 years after cervical disc replacement. Eur Spine J 20(9):1417-1426. https://doi. org/10.1007/s00586-011-1722-9

16. McAfee PC, Cunningham BW, Devine J, Williams E, Yu-Yahiro J (2003) Classification of heterotopic ossification (HO) in artificial disk replacement. J Spinal Disorders Tech 16(4):384-389

17. Mehren C, Suchomel P, Grochulla F, Barsa P, Sourkova P, Hradil J, Korge A, Mayer HM (2006) Heterotopic ossification in total cervical artificial disc replacement. Spine 31(24):2802-2806. https://doi.org/10.1097/01.brs.0000245852.70594.d5

18. Kellgren JH, Lawrence JS (1957) Radiological assessment of osteo-arthrosis. Ann Rheum Dis 16(4):494-502

19. Symposium on Population Studies in Relation to Chronic Rheumatic Diseases R, Ball J, Jeffrey MR, Kellgren JH, Council for International Organizations of Medical S, University of Manchester. Department of R (1963) The epidemiology of chronic rheumatism; Volume 2: Atlas of standard radiographs of arthritis. Blackwell Scientific Publications, Oxford

20. Burkus JK, Haid RW, Traynelis VC, Mummaneni PV (2010) Long-term clinical and radiographic outcomes of cervical disc replacement with the Prestige disc: results from a prospective randomized controlled clinical trial. J Neurosurg Spine 13(3):308318. https://doi.org/10.3171/2010.3.SPINE09513

21. Dejaegher J, Walraevens J, van Loon J, Van Calenbergh F, Demaerel P, Goffin J (2017) 10-year follow-up after implantation of the Bryan Cervical Disc Prosthesis. Eur Spine J 26(4):1191-1198. https://doi.org/10.1007/s00586-016-4897-2

22. Hisey MS, Zigler JE, Jackson R, Nunley PD, Bae HW, Kim KD, Ohnmeiss DD (2016) Prospective, randomized comparison of one-level Mobi-C cervical total disc replacement vs. anterior cervical discectomy and fusion: results at 5-year follow-up. Int J Spine Surg 10:10. https://doi.org/10.14444/3010

23. Loumeau TP, Darden BV, Kesman TJ, Odum SM, Van Doren BA, Laxer EB, Murrey DB (2016) A RCT comparing 7-year clinical outcomes of one level symptomatic cervical disc disease (SCDD) following ProDisc-C total disc arthroplasty (TDA) versus anterior cervical discectomy and fusion (ACDF). Eur Spine J 25(7):22632270. https://doi.org/10.1007/s00586-016-4431-6

24. Mehren C, Heider F, Siepe CJ, Zillner B, Kothe R, Korge A, Mayer HM (2017) Clinical and radiological outcome at 10 years of follow-up after total cervical disc replacement. Eur Spine J https://doi.org/10.1007/s00586-017-5204-6

25. Phillips FM, Geisler FH, Gilder KM, Reah C, Howell KM, McAfee PC (2015) Long-term outcomes of the US FDA IDE prospective, randomized controlled clinical trial comparing PCM cervical disc arthroplasty with anterior cervical discectomy and fusion. Spine 40(10):674-683. https://doi.org/10.1097/BRS.0000000000 000869

26. Radcliff K, Coric D, Albert T (2016) Five-year clinical results of cervical total disc replacement compared with anterior discectomy and fusion for treatment of 2-level symptomatic degenerative disc disease: a prospective, randomized, controlled, multicenter investigational device exemption clinical trial. J Neurosurg Spine 25(2):213-224. https://doi.org/10.3171/2015.12.SPINE15824

27. Skeppholm M, Lindgren L, Henriques T, Vavruch L, Lofgren H, Olerud C (2015) The Discover artificial disc replacement versus fusion in cervical radiculopathy - a randomized controlled outcome trial with 2-year follow-up. Spine J 15(6):1284-1294. https ://doi.org/10.1016/j.spinee.2015.02.039

28. Vaccaro A, Beutler W, Peppelman W, Marzluff JM, Highsmith J, Mugglin A, DeMuth G, Gudipally M, Baker KJ (2013) Clinical outcomes with selectively constrained SECURE-C cervical disc arthroplasty: two-year results from a prospective, randomized, controlled, multicenter investigational device exemption study. Spine 38(26):2227-2239. https://doi.org/10.1097/BRS.00000 00000000031

29. Wigfield C, Gill S, Nelson R, Langdon I, Metcalf N, Robertson J (2002) Influence of an artificial cervical joint compared with fusion on adjacent-level motion in the treatment of degenerative cervical disc disease. J Neurosurg 96(1 Suppl):17-21

30. Hilibrand AS, Robbins M (2004) Adjacent segment degeneration and adjacent segment disease: the consequences of spinal fusion? Spine J 4(6 Suppl):190S-194S. https://doi.org/10.1016/j. spinee.2004.07.007

31. Radcliff K, Davis RJ, Hisey MS, Nunley PD, Hoffman GA, Jackson RJ, Bae HW, Albert T, Coric D (2017) Long-term evaluation of cervical disc arthroplasty with the Mobi-C(c) cervical disc: a randomized, prospective, multicenter clinical trial with seven-year follow-up. Int J Spine Surg 11:31. https://doi.org/10.14444/4031

32. Zou S, Gao J, Xu B, Lu X, Han Y, Meng H (2017) Anterior cervical discectomy and fusion (ACDF) versus cervical disc arthroplasty (CDA) for two contiguous levels cervical disc degenerative disease: a meta-analysis of randomized controlled trials. Eur Spine J 26(4):985-997. https://doi.org/10.1007/s00586-016-4655-5

33. Chen J, Wang X, Bai W, Shen X, Yuan W (2012) Prevalence of heterotopic ossification after cervical total disc arthroplasty: a meta-analysis. Eur Spine J 21(4):674-680. https://doi. org/10.1007/s00586-011-2094-x

34. Kong L, Ma Q, Meng F, Cao J, Yu K, Shen Y (2017) The prevalence of heterotopic ossification among patients after cervical artificial disc replacement: a systematic review and meta-analysis. Medicine 96(24):e7163. https://doi.org/10.1097/md.0000000000 007163

35. Utter PA, Kerr E, Cavanaugh D, Stone M, Nunley P (2015a) Endplate coverage correlates with heterotopic ossification in one-and two-level cervical TDR patients. J Neurosurg 123(2):A520. https ://doi.org/10.3171/2015.8.JNS.AANS2015abstracts

36. Lee DH, Cho JH, Hwang CJ, Lee CS, Cho SK, Kim C, Ha JK (2018) What is the fate of pseudarthrosis detected 1 year after anterior cervical discectomy and fusion? Spine 43(1):E23-E28. https://doi.org/10.1097/brs.0000000000002077

37. Hilibrand AS, Carlson GD, Palumbo MA, Jones PK, Bohlman HH (1999) Radiculopathy and myelopathy at segments adjacent to the site of a previous anterior cervical arthrodesis. J Bone Jt Surg Am 81(4):519-528

38. Xia XP, Chen HL, Cheng HB (2013) Prevalence of adjacent segment degeneration after spine surgery: a systematic review and meta-analysis. Spine 38(7):597-608. https://doi.org/10.1097/ BRS.0b013e318273a2ea

39. Kelly MP, Eliasberg CD, Riley MS, Ajiboye RM, SooHoo NF (2018) Reoperation and complications after anterior cervical discectomy and fusion and cervical disc arthroplasty: a study of 52,395 cases. Eur Spine J. 27(6):1432-1439. https://doi. org/10.1007/s00586-018-5570-8 (Epub 2018 Mar 31 PMID: 29605899)

40. Dong L, Xu Z, Chen X, Wang D, Li D, Liu T, Hao D (2017) The change of adjacent segment after cervical disc arthroplasty compared with anterior cervical discectomy and fusion: a meta-analysis of randomized controlled trials. Spine J 17(10):1549-1558. https://doi.org/10.1016/j.spinee.2017.06.010 (Epub 2017 Jun 15. Review) 
41. Chen C, Zhang X, Ma X (2017) Durability of cervical disc arthroplasties and its influence factors: a systematic review and a network meta-analysis. Medicine (Baltimore) 96(6):e5947. https ://doi.org/10.1097/MD.0000000000005947 (Review, PMID: 28178135)

42. Qureshi SA, McAnany S, Goz V, Koehler SM, Hecht AC (2013) Cost-effectiveness analysis: comparing single-level cervical disc replacement and single-level anterior cervical discectomy and fusion: clinical article. J Neurosurg Spine 19(5):546-554. https ://doi.org/10.3171/2013.8.spine12623

43. Ament JD, Yang Z, Nunley P, Stone MB, Lee D, Kim KD (2016) Cost utility analysis of the cervical artificial disc vs fusion for the treatment of 2-level symptomatic degenerative disc disease: 5-year follow-up. Neurosurgery 79(1):135-145. https://doi.org/10.1227/ neu.0000000000001208

44. McAnany SJ, Overley S, Baird EO, Cho SK, Hecht AC, Zigler JE, Qureshi SA (2014) The 5-year cost-effectiveness of anterior cervical discectomy and fusion and cervical disc replacement: a Markov analysis. Spine 39(23):1924-1933. https://doi. org/10.1097/brs.0000000000000562

45. Jee YM, Bak JS, Weinlander E, Anderson PA (2016) Comparing nonrandomized observational studies with randomized controlled trials in cervical disc arthroplasty: a meta-analysis. Spine 41(5):419-428. https://doi.org/10.1097/BRS.0000000000001377

46. Grob D, Porchet F, Kleinstuck FS, Lattig F, Jeszenszky D, Luca A, Mutter U, Mannion AF (2010) A comparison of outcomes of cervical disc arthroplasty and fusion in everyday clinical practice: surgical and methodological aspects. Eur Spine J 19(2):297-306. https://doi.org/10.1007/s00586-009-1194-3

Publisher's Note Springer Nature remains neutral with regard to jurisdictional claims in published maps and institutional affiliations.

\section{Affiliations}

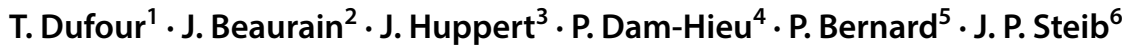

T. Dufour

TH.DUFOUR@ramsaygds.fr

1 Institut Parisien du Dos, Clinique Geoffroy Saint Hilaire, 6 Rue Lacépède, 75005 Paris, France

2 Neuro-Surgery Department, University Hospital, Dijon, France

3 Neuro-Surgery Department, Clinique du Parc, St-Priest-en-Jarez, France
4 Neuro-Surgery Department, Hopital de La Cavale Blanche, Brest, France

5 Orthopaedic Department, Centre Aquitain du Dos, Mérignac, France

6 Orthopaedic Surgery Department, University Hospital, Strasbourg, France 